\title{
Monitoring the Doping and Diffusion Characteristics of Mn Dopants in Cesium Lead Halide Perovskites
}

\author{
Tugrul Guner, ${ }^{\dagger}$ Baris Akbali, $^{\ddagger}{ }^{\oplus 0}$ Mehmet Ozcan, $^{\text {I }}$ Gokhan Topcu, $^{\dagger}$ Mustafa M. Demir, $^{\dagger \oplus}$ \\ and Hasan Sahin*,I, \&(0) \\ ${ }^{\dagger}$ Department of Materials Science and Engineering, Izmir Institute of Technology, 35430 Izmir, Turkey \\ ${ }^{\ddagger}$ Department of Physics, Izmir Institute of Technology, 35430 Izmir, Turkey \\ ${ }^{\text {II } D e p a r t m e n t ~ o f ~ P h o t o n i c s, ~ I z m i r ~ I n s t i t u t e ~ o f ~ T e c h n o l o g y, ~} 35430$ Izmir, Turkey \\ ${ }^{\S}$ ICTP-ECAR Eurasian Center for Advanced Research, Izmir Institute of Technology, 35430 Izmir, Turkey
}

ABSTRACT: Cesium lead perovskites, in the form of $\mathrm{CsPbX}_{3}$ or $\mathrm{Cs}_{4} \mathrm{PbX}_{6}$, have been widely used for various optoelectronic applications due to their exceptionally good optical properties. In this study, the effect of Mn doping on the structural and optical properties of cesium lead halide perovskite crystals are investigated from both experimental and theoretical points of view. It is found that adding $\mathrm{MnCl}_{2}$ during the synthesis not only leads to a $\mathrm{Mn}$-driven structural phase transition from $\mathrm{Cs}_{4} \mathrm{PbBr}_{6}$ to $\mathrm{CsPbCl}_{3}$ but also triggers the $\mathrm{Br}^{-}$to $\mathrm{Cl}^{-}$halide exchange. On the other hand, it is observed that, under UV illumination, the color of Mn-doped crystals changes from orange to blue in approximately $195 \mathrm{~h}$. While the intensity of Mn-originated photoluminescence emission exponentially decays in time, the intensity of $\mathrm{CsPCCl}_{3}$-originated emission remains unchanged. In addition, diffusive motion of $\mathrm{Mn}$ ions results in both a growing population of $\mathrm{MnO}_{2}$ at the surface and transition of the host into a cesium-rich $\mathrm{Cs}_{4} \mathrm{PbCl}_{6}$ phase.

\section{INTRODUCTION}

As a member of the colloidal semiconductor nanocrystal (NC) family, cesium lead halide perovskites in the form of $\mathrm{CsPbX}_{3}$ ( $\mathrm{X}: \mathrm{Cl}^{-}, \mathrm{Br}^{-}, \mathrm{I}^{-}$) offer outstanding optical properties such as high photoluminescence quantum yield (PLQY) and defect tolerance and wavelength tunability. ${ }^{1-7}$ Moreover, these materials are solution-processable, and therefore, morphology of perovskite NCs can be easily controlled ${ }^{8}$ (i.e., nanocubes, ${ }^{2,9}$ nanowire, ${ }^{10-12}$ nanoplatelets ${ }^{13-15}$ ) or composition of NCs can be tailored. ${ }^{2-5}$ In this sense, either by adjusting the NCs size through morphology control or via anion-exchange reactions by adjusting the composition, ${ }^{3,16}$ one can cover the full visible spectrum or can tune their optical properties. ${ }^{5,17-20}$ Cesium lead perovskites are potential candidates in a variety of optoelectronic and photonic applications such as solar cells, ${ }^{21,22}$ photodetectors, ${ }^{23,24}$ display, ${ }^{25,26}$ light-emitting diodes, $^{27-29}$ and lasers. ${ }^{30-32}$

Doping is a well-known strategy that may lead to novel functionalities and significant improvement in device efficiency. ${ }^{33-44}$ To date, various ions that are used as dopants for cesium halide perovskite NCs have been reported. ${ }^{45-50}$ Among those, doping of cesium lead perovskites with $\mathrm{Mn}$ ions began to attract significant attention recently since the presence of $\mathrm{Mn}$ ions can add novel optical and magnetic features to NCs. ${ }^{50-54}$ For instance, $\mathrm{Mn}$ ions open an extra emission channel at $\sim 590$ $\mathrm{nm}$ due to transfer of exciton energy from host to $d$-states of $\mathrm{Mn} \cdot{ }^{55-57}$ In other words, dopant-induced emission is the result

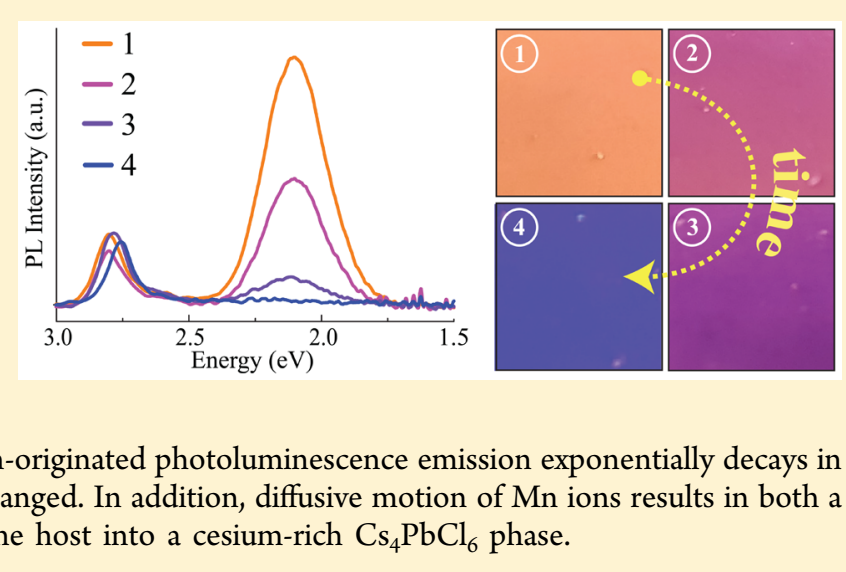

of radiative transition of electrons between host and the intragap states of dopant impurities. ${ }^{41}$ During this transition, energy is transferred from the electron-hole pair created via excessive energy of absorbed photon to the dopant levels, and as a result, dopant-induced emission occurs due to the electron-hole recombination taking place in the midgap states of dopant impurities. ${ }^{42,43}$ However, doping may create charge and size imbalance at the host lattice of these NCs that causes changes in both the crystal structure and the emission characteristics. ${ }^{41,58-60}$

In this study, the effect of $\mathrm{Mn}$ ions on the structural and spectral properties of cesium lead halide perovskite crystals was investigated by performing experiments and first-principle calculations. First, it was observed that the presence of $\mathrm{Mn}$ ions causes a phase transition from $\mathrm{Cs}_{4} \mathrm{PbBr}_{6}$ to $\mathrm{CsPCl}_{3}$ during the doping process. Moreover, dopant-induced emission was found to decay exponentially over time due to diffusion of $\mathrm{Mn}$ atoms through the crystal surface. During the diffusion, apart from the optical degradation, structural changes, indicating the formation of $\mathrm{Cs}_{4} \mathrm{PbCl}_{6}$ phase, were also observed. At last, we performed density functional theory (DFT) and room-temperature molecular dynamics calculations to investigate the structural change and diffusion-driven optical

Received: March 16, 2018

Revised: $\quad$ May 3, 2018

Published: May 4, 2018 
degradation. As a result, this work presents a comprehensive view on the doping process, covering both the pre- and postdoping conditions.

\section{METHODOLOGY}

Experimental Methodology. Materials. Cesium bromide (CsBr, 99.9\%, Sigma-Aldrich), lead(II) bromide $\left(\mathrm{PbBr}_{2}, \geq 98 \%\right.$, Sigma-Aldrich), manganese(II) chloride tetrahydrate $\left(\mathrm{MnCl}_{2}\right.$. $4 \mathrm{H}_{2} \mathrm{O} \geq 98 \%$, Sigma-Aldrich), oleic acid (OA, 90\%, Alfa Aesar), oleylamine (OAm, 90\%, Sigma-Aldrich), dimethylformamide (DMF, $\geq 99.9 \%$, Tekkim), hexane ( $\geq 98 \%$, SigmaAldrich), and toluene ( $\geq 99 \%$, Merck) were purchased and used as received without any further purification.

Synthesis of Undoped Cesium Lead Perovskite. Following the synthesis method, ${ }^{61} 0.4 \mathrm{mmol}$ of $\mathrm{CsBr}$ and $0.4 \mathrm{mmol}$ of $\mathrm{PbBr}_{2}$ were dissolved in $10 \mathrm{~mL}$ of $\mathrm{DMF}$, and then ligands $\mathrm{OA}$ $(1.0 \mathrm{~mL})$ and $\mathrm{OAm}(0.5 \mathrm{~mL})$ were added to the solution under vigorous stirring. An aliquot of $0.5 \mathrm{~mL}$ from the prepared $\mathrm{Cs}^{+}$ and $\mathrm{Pb}^{2+}$ ions source was injected into $5 \mathrm{~mL}$ of toluene under vigorous stirring. The solution turned an explicit green color immediately, and after 3-4 min, it was centrifuged under 6000 $\mathrm{rpm}$ for $5 \mathrm{~min}$. Precipitates were redispersed in hexane.

Synthesis of Mn-Doped Cesium Lead Perovskite. As $\mathrm{Mn}^{2+}$ source, $\mathrm{MnCl}_{2}(10 \mathrm{mmol})$ was dissolved in $10 \mathrm{~mL}$ of DMF. To obtain Mn-doped cesium lead perovskite, $0.5 \mathrm{~mL}$ of the $\mathrm{Cs}^{+}$ and $\mathrm{Pb}^{2+}$ ions source and $0.5 \mathrm{~mL}$ of the $\mathrm{Mn}$ source were injected into $5 \mathrm{~mL}$ of toluene simultaneously under vigorous stirring. The solution became a bright green-yellow color rapidly, and after 3-4 min, it was centrifuged under $6000 \mathrm{rpm}$ for $5 \mathrm{~min}$. Precipitates were redispersed in hexane.

Characterization. The diffraction profiles of the Cesium perovskites were recorded with an X-ray diffractometer (XRD, X' Pert Pro, Philips, Eindhoven, The Netherlands). Emission spectra were determined using an USB2000+ spectrometer (Ocean Optics Inc., Dunedin, FL) via a premium fiber cable. Raman (Horiba Xplora Plus) was used to determine fingerprint Raman-active vibrations of Cs-perovskite structures.

Computational Methodology. Density functional theorybased calculations were performed using the projector augmented wave (PAW $)^{62,63}$ potentials as implemented in the Vienna ab initio Simulation Package (VASP). ${ }^{64,65}$ The local density approximation (LDA) ${ }^{66}$ was used to describe the exchange and correlation potential. ${ }^{67}$ The Bader technique was used to determine the charge transfer between the atoms. ${ }^{68}$

A plane-wave basis set with a kinetic energy cutoff of $500 \mathrm{eV}$ was used for all of the calculations. The total energy difference between the sequential steps in the iterations was taken to be $10^{-5} \mathrm{eV}$ as the convergence criterion. The total force in the unitcell was reduced to a value less than $10^{-4} \mathrm{eV} / \AA$. $\Gamma$-centered k-point meshes of $3 \times 3 \times 3$ and $3 \times 3 \times 1$ were used for bulk and surface relaxations, respectively. For $\mathrm{Pb}$ - and Cs-terminated surfaces, vacuum spaces of $10 \AA$ were incorporated to avoid interaction with neighboring surfaces. Gaussian smearing of 0.1 $\mathrm{eV}$ was used for electronic density of states calculations. Spinpolarized calculations were performed in all cases. The cohesive energy per atom was calculated using the formula

$$
E_{\mathrm{Coh}}=\left[\sum_{i} n_{\mathrm{atom}(i)} E_{\mathrm{atom}(i)}-E_{\mathrm{system}}\right] / n_{\text {total }}
$$

where $E_{\text {atom(i) }}$ is isolated single atom energies for the $i$ th atom, while $i$ stands for the number of all atoms for the same species, $n_{\text {total }}$ represents the total number of atoms, and $n_{\text {atom }(i)}$ shows the numbers of same kind of atoms in the unit cell, respectively.

\section{RESULTS}

Mn Doping-Driven Structural Transition from $\mathrm{Cs}_{4} \mathrm{PbBr}_{6}$ to $\mathrm{CsPbCl}_{3}$ Phase. Among those possible $\mathrm{MnX}_{2}$ (X: $\mathrm{Cl}^{-}, \mathrm{Br}^{-}$, and $\mathrm{I}^{-}$) precursors, $\mathrm{MnCl}_{2}$ was already reported as the one that favors the $\mathrm{Mn}$ incorporation most since the bond dissociation energy of the $\mathrm{Mn}-\mathrm{Cl}$ is closer to the one of $\mathrm{Pb}-\mathrm{Cl}$ compared the other possible $\mathrm{Mn}-\mathrm{X}$ precursors and their corresponding $\mathrm{Pb}-\mathrm{X}$ bonds. ${ }^{57}$ To achieve doping, $\mathrm{MnCl}_{2}$ was used during the synthesis of cesium lead preovskite crystals, and it was found that its usage leads to significant modification in its structural, vibrational, and electronic properties (Figure 1).
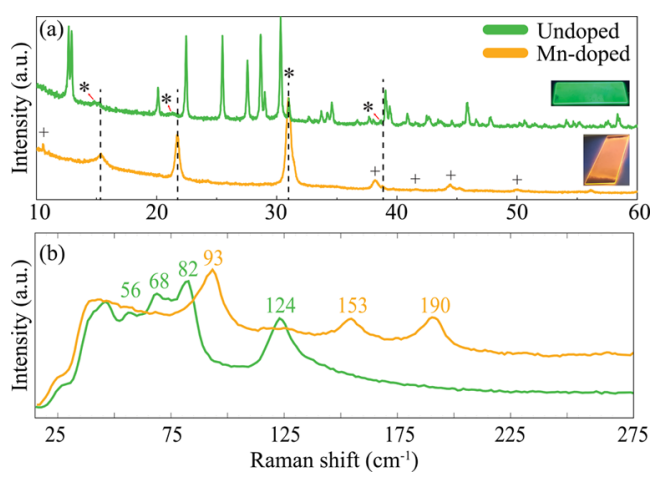

Figure 1. (a) X-ray diffraction and (b) Raman spectra of the undoped and Mn-doped perovskite crystals.

While the structural characteristics of the crystals are monitored by XRD and Raman spectroscopy, their electronic and optical properties are characterized via experimentally observed PL spectra and theoretically calculated band dispersions.

Figure 1a shows the reflection signals of both undoped and Mn-doped samples collected from X-ray diffraction. Apparently, diffraction pattern represented with a green line show that the $\mathrm{Cs}_{4} \mathrm{PbBr}_{6}$ phase forms first when the $\mathrm{Cs}^{+}$and $\mathrm{Pb}^{2+}$ sources are solely employed. ${ }^{69}$ As reported previously, ${ }^{69}$ in addition to $\mathrm{Cs}_{4} \mathrm{PbBr}_{6}$ there are also weak signals detected from small $\mathrm{CsPbBr}_{3}$ crystals marked with *. However, the Mn-doped perovskite structure that shows orange color under UV light has sharp signals at $2 \theta: 15^{\circ}, 22^{\circ}, 31^{\circ}$, and $38^{\circ}$ (black dashed lines). These intense XRD reflections not only indicate the formation of high crystalline Mn-doped perovskite material but also reveal the significant modification in crystal symmetry and structural transformation. Apparently, the XRD signals of the Mn-doped structure perfectly match with the tetragonal phase of $\mathrm{CsPbCl}$ represented with black dashed line (JCPDS 18-0366). Therefore, during the manganese-doping process that is done by using $\mathrm{MnCl}_{2}$ molecules, $\mathrm{Br}-\mathrm{Cl}$ halide exchange reaction also takes place. It is also seen that following the $\mathrm{Br}-\mathrm{Cl}$ exchange weak signals that belong to the $\mathrm{Cs} \mathrm{PbBr}_{3}$ become quite intense in the well-chlorinated crystal structure and $\mathrm{Mn}$-doped sample contains no $\mathrm{Cs}_{4} \mathrm{PbBr}_{6}$ signals. On the other hand, signals marked with + correspond to excessive $\mathrm{Mn}$ ions that resulted in a trace amount of $\alpha-\mathrm{MnO}_{2}$ (JCPDS 44-0141) along the sample. Therefore, it is clear from XRD spectra that adding $\mathrm{MnCl}_{2}$ / DMF solution simultaneously with the $\mathrm{Cs}^{+}$and $\mathrm{Pb}^{2+}$ ions source into toluene leads to a phase transformation from $\mathrm{Cs}_{4} \mathrm{PbBr}_{6}$ to $\mathrm{CsPbCl}_{3}$. 
To monitor how the vibrational characteristics of the crystal evolve during the doping procedure, time-dependent roomtemperature Raman measurement was carried out using 785 nm laser excitation. As shown in Figure 1b, Raman peaks at 56, 68,82 , and $124 \mathrm{~cm}^{-1}$ were obtained from the undoped sample, indicating the formation of $\mathrm{Cs}_{4} \mathrm{PbBr}_{6}$ phase. On the other hand, the Raman spectrum of the Mn-doped sample indicates that the peak at $124 \mathrm{~cm}^{-1}$ that originates from the $\mathrm{Pb}-\mathrm{Br}$ phonon modes in the $\left[\mathrm{PbBr}_{6}\right]^{-}$octahedron ${ }^{70}$ vanishes; however additional Raman shifts at 93, 153, and $190 \mathrm{~cm}^{-1}$ appear. Among these, while the peak at $93 \mathrm{~cm}^{-1}$ corresponds to the longitudinal optic (LO) mode of $\mathrm{CsPbl}_{3} \mathrm{crystal}^{71}$ the modes at 153 and $190 \mathrm{~cm}^{-1}$ stem from the $\mathrm{Mn}$ atoms. As a result, Raman spectra also verify that using $\mathrm{MnCl}_{2}$ together with $\mathrm{Cs}^{+}$ and $\mathrm{Pb}^{2+}$ ions source during the synthesis significantly modifies the structure of resulting cesium lead perovskite phase.

Moreover, how the optical properties of the perovskite are modified by Mn dopants was investigated by PL spectroscopy. As shown in Figure 2a, there is a single narrow emission peak at
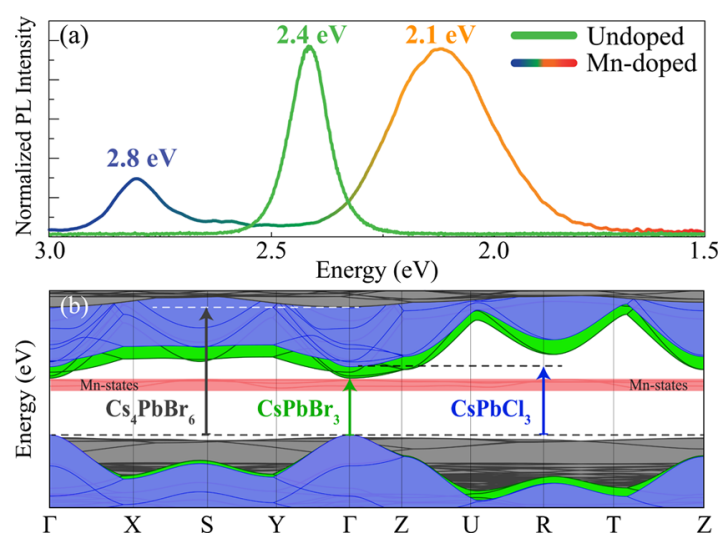

Figure 2. (a) PL spectra and (b) electronic band dispersion of undoped and $\mathrm{Mn}$-doped samples.

$2.4 \mathrm{eV}$ for the undoped structure. In this sense, emission at 2.4 $\mathrm{eV}$ originates from the $\mathrm{Cs} \mathrm{PbBr}_{3}$ domains (their presence was already verified in Figure 1a). ${ }^{72}$ However, as shown in Figure $2 \mathrm{a}$, two prominent peaks were observed in the PL spectrum after the Mn-doping procedure.
The ground-state electronic structures were also investigated by performing density functional theory calculations. First, cohesive energy calculations indicated that $\mathrm{CsPbBr}_{3}$ and $\mathrm{CsPbCl}_{3}$ structures have cohesive energies of 3.37 and 3.67 $\mathrm{eV} /$ atom, and therefore, as long as there is a Cl-rich environment, the formation of chlorine-exchanged domains is energetically more favorable. The calculated electronic band structures of $\mathrm{CsPbCl}_{3}, \mathrm{Cs} \mathrm{PbBr}_{3}$, and $\mathrm{Mn}$-doped $\mathrm{CsPCl}_{3}$ are shown in Figure $2 \mathrm{~b}$. It is seen that while the halide exchange in $\mathrm{CsPbX}_{3}$ leads to ignorable modification in the electronic band dispersion (band edges of both crystals lie at $\Gamma$ point), the $\mathrm{CsPbCl}_{3}$ structure has wider bandgap than that of $\mathrm{CsPbBr}$. Thus, DFT calculations on the electronic structure, shown in Figure $2 \mathrm{~b}$, showed that $(\mathrm{i})$ the emission at $2.8 \mathrm{eV}(443 \mathrm{~nm})$ is due to the $\mathrm{CsPbl}_{3}$ phase which has a direct bandgap at the $\Gamma$ high symmetry point and (ii) the presence of the Mn dopants leads to midgap states at the vicinity of $2.1 \mathrm{eV}(589 \mathrm{~nm})$.

Optical Stability of $\mathrm{Mn}$-Doped $\mathrm{CsPbCl}_{3}$. To investigate the optical stability of $\mathrm{Mn}$-doped $\mathrm{CsPbCl}_{3}$, its emission was tracked over time. As shown in Figure 3a, Mn-doped $\mathrm{CsPbCl}_{3}$ casted on the glass slide emits orange color under UV illumination $(254 \mathrm{~nm})$. It is seen from the photograph of the UV-illuminated sample that the emission of Mn-doped structure rapidly changes from orange to bluish color and after $195 \mathrm{~h}$ under ambient conditions, perovskite completely turned into blue.

To verify color change over time, the PL spectrum of the orange perovskite crystal was registered at various times as presented in Figure 3. It is seen that while the intensity of the dopant-originated emission at $2.1 \mathrm{eV}$ decreases rapidly, the emission of the host crystal $\mathrm{CsPbCl}_{3}$ at $2.8 \mathrm{eV}$ remains almost the same. Finally, the emission at $2.1 \mathrm{eV}$, that leads to the orange coloring of the structure, completely disappears after $195 \mathrm{~h}$. Here, the rapid decrease in the dopant-induced emission over time is a kind of self-purification process that takes place via removal of dopant atoms from the crystal lattice through the surface by diffusion. ${ }^{40,44,73}$

Moreover, the rate of change in the Mn-induced emission is shown in Figure 3c, indicating that the observed data well fits to the exponential decay equation $y-y_{0}=A e^{-t / c}$, where $y_{0}=$ 0.094, $A=0.884$, and $c=54.219$. Apparently, the exponential decrease of the peak stems from the diffusion of $\mathrm{Mn}$ atoms
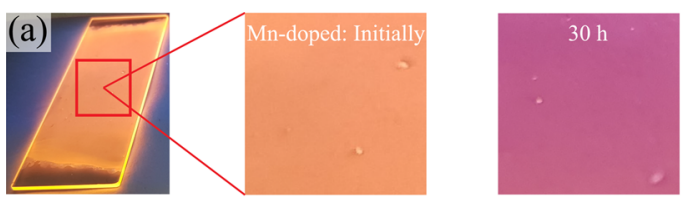

(b)

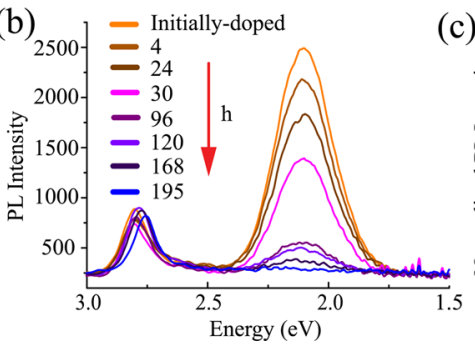

(c)

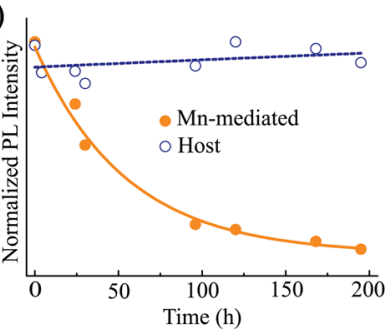

(d)

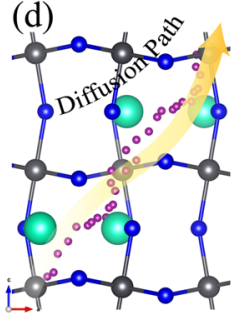

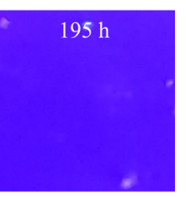

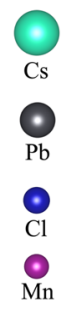

Figure 3. (a) Color change of the Mn-doped $\mathrm{CsPbCl}_{3}$ perovskite under UV illumination ( $\left.254 \mathrm{~nm}\right)$ in time. Photographs, from left to right, represent the Mn-doped $\mathrm{CsPCl}_{3}$ perovskite from its initial moment of casting (Mn-doped: initially) to $195 \mathrm{~h}$ later under ambient conditions. (b, c) Change of related PL spectrum and PL intensity of $\mathrm{Mn}$-doped $\mathrm{CsPbCl}_{3}$ perovskite under $\mathrm{UV}$ illumination $(254 \mathrm{~nm})$ in time, respectively. (d) Possible diffusion path of $\mathrm{Mn}$ atoms obtained from room-temperature molecular dynamics calculations. 
from lattice to surface. At this point, for further theoretical examination of the possibility of diffusion of $\mathrm{Mn}$ atoms in the $\mathrm{CsPbCl}_{3}$ crystal structure, ab initio molecular dynamics (MD) calculations were also performed. Constant temperature $\mathrm{MD}$ simulations for 10 ps duration time, as shown in Figure $3 \mathrm{~d}$, reveal that while the crystal structure remains stable at room temperature, $\mathrm{Mn}$ atoms can easily diffuse in the lattice sites by passing from the vicinity of $\mathrm{Cs}$ and $\mathrm{Pb}$ sites.

Modification in the crystal structure triggered by the diffusion of $\mathrm{Mn}$ atoms is also investigated by X-ray diffraction and Raman spectroscopy measurements at various times after casting the crystal dispersion from hexane. As shown in Figure $4 \mathrm{a}$, additional reflection signals became visible after $96 \mathrm{~h}$,
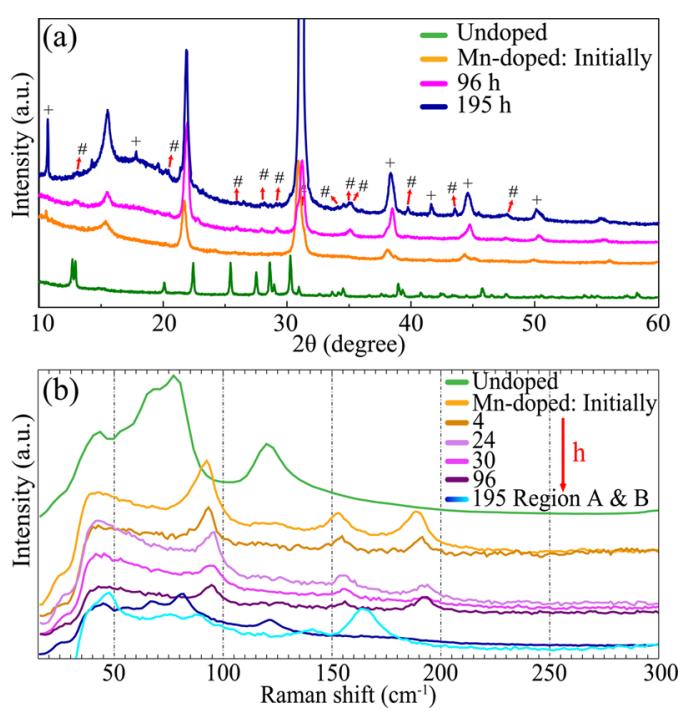

Figure 4. Structural change of the $\mathrm{Mn}$-doped $\mathrm{CsPbCl}_{3}$ perovskite tracked over time by collecting (a) crystallographic information via $\mathrm{X}$ ray diffraction pattern and (b) vibrational modes via Raman scattering modes.

indicating structural modification. The other XRD signals marked with \# clearly indicate the reformation of the $\mathrm{Cs}_{4} \mathrm{PbX}_{6}$ (where $\mathrm{X}$ is $\mathrm{Br}$ or $\mathrm{Cl}$ ) phase after $\mathrm{Mn}$ segregation. It is also seen that the XRD spectrum at $96 \mathrm{~h}$ includes some slightly blueshifted $2 \theta$ values that resemble the undoped $\mathrm{Cs}_{4} \mathrm{PbBr}_{6}$ phase. However, the shift in signals is simply due to the $\mathrm{Br}-\mathrm{Cl}$ exchange, which takes place during the addition of $\mathrm{MnCl}_{2}$.

At the end of $195 \mathrm{~h}$, an obvious broad background signal appears between 12 and $20^{\circ}$. This feature is called as amorphous halo. The occurrence of this signal after a long time duration may suggest the detachment of OA and OAm. Moreover, the number of XRD signals originates from the increase of the $\mathrm{Cs}_{4} \mathrm{PbCl}_{6}$ domain. On the other hand, the intensity of the $\alpha-\mathrm{MnO}_{2}$ characteristic signals (marked with + ) increases over time. This increase can be explained by the growing population of $\mathrm{MnO}_{2}$ at the crystal surface. It can be concluded that $\mathrm{Mn}$-doped $\mathrm{CsPbCl}_{3}$ crystals change their phase from $\mathrm{Mn}$-doped tetragonal phase $\mathrm{CsPbCl}_{3}$ to $\mathrm{Cs}_{4} \mathrm{PbCl}_{6}$ during the Mn-diffusion process.

Time-dependent room-temperature Raman measurements are also shown in Figure $4 \mathrm{~b}$. The prominent modes of $\mathrm{Mn}$ doped sample at 92,152 , and $190 \mathrm{~cm}^{-1}$ appear upon doping by $\mathrm{Mn}$ atoms. $\mathrm{Mn}$-induced vibrational modes of the crystal, 152 and $190 \mathrm{~cm}^{-1}$, were observed to vanish over time. After $195 \mathrm{~h}$, two different regions were observed. In region $\mathrm{A}$, which is presented with a navy blue line, the Raman shift became almost identical with the undoped one, but a few wavenumbers shifted due to halide exchange. In region $\mathrm{B}$, presented with a turquoise line, a prominent peak occurs at $162 \mathrm{~cm}^{-1}$, which is the indication of $\mathrm{MnO}_{2}{ }^{74}$

As a result, it is observed experimentally that there is a clear optical degradation of the Mn-induced emission at $2.1 \mathrm{eV}$ over time, implying the diffusion of $\mathrm{Mn}$ atoms. Meanwhile, during the diffusion process, additional signals began to appear in both XRD and Raman measurements. Therefore, it can be concluded that the diffusion of $\mathrm{Mn}$ atoms leads to both optical and structural instabilities.

Diffusion Dynamics at the Surface. The diffusive motion of $\mathrm{Mn}$ atoms toward surface and the transition from $\mathrm{CsPbCl}_{3}$ phase to $\mathrm{Cs}_{4} \mathrm{PbCl}_{6}$ were also investigated through first-principle calculations. As shown in Figure 5, two possible surface types,

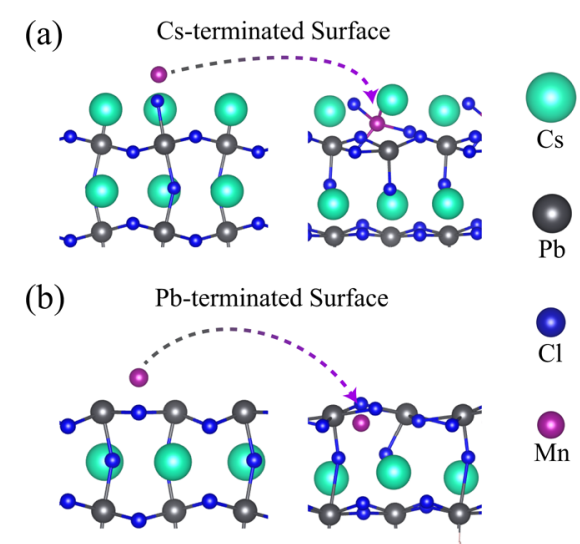

Figure 5. Calculated adsorption sites on the Cs- and Pb-terminated surfaces of $\mathrm{CsPbCl}_{3}$.

namely Cs- and $\mathrm{Pb}$-terminated surfaces, were considered to investigate the absorption energy of $\mathrm{Mn}$ atom. The calculations reveal that the binding energy of the $\mathrm{Mn}$ atom on the Cs- and $\mathrm{Pb}$-terminated surfaces of $\mathrm{CsPbCl}_{3}$ are 4.74 and $5.19 \mathrm{eV}$, respectively. Bader charge analysis indicates that $\mathrm{Mn}$ atom donates $1.2 e$ and $1.0 e$ to $\mathrm{Cs}$ - and $\mathrm{Pb}$-terminated surfaces, respectively. Therefore, considering the binding energy of $\mathrm{Mn}$ atoms inside the crystal structure, which is $1.24 \mathrm{eV}$ at the most favorable lattice site, diffusive motion toward the surface is found to be inevitable.

On the other hand, the absorption energies of $\mathrm{Mn}$ atoms on the Cs- and $\mathrm{Pb}$-terminated surfaces are significantly higher than the adsorption energies of OA and OAm, which are 698 and $463 \mathrm{meV}$ for the Cs-terminated and 221 and $874 \mathrm{meV}$ for the $\mathrm{Pb}$-terminated surface, respectively. ${ }^{75}$ Therefore, the surface of the perovskite crystals, including either Cs- or Pb-terminated surfaces, prefer to bind $\mathrm{Mn}$ atoms by leaving the ligands. In such a case, expelled ligands then can bind to $\mathrm{CsPCl}_{3}$ surfaces that do not contain any $\mathrm{Mn}$ atoms and lead to ligand-mediated phase transformation from $\mathrm{CsPbCl}_{3}$ to $\mathrm{Cs}_{4} \mathrm{PbCl}_{6}$. Among these ligands (OA and $\mathrm{OAm})$, it was already reported that $\mathrm{OAm}$ by itself can trigger this process. ${ }^{76}$

Note that during the doping process, only some limited amount of the $\mathrm{Mn}(\leq 37 \%)$ can be doped into the $\mathrm{CsPbCl}_{3}$ lattice as substitutional defects up to a $37 \%$ doping ratio were reported as achieved maximally when the synthesis method followed in this study was used. ${ }^{61}$ In any case, the crystals were found to be either Mn-doped ( $\leq 37 \%)$ or undoped (remain as 
neat host $\mathrm{CsPbCl}_{3}$ crystals $\geq 63 \%$ ), and the entire sample presents clear $\mathrm{CsPbCl}_{3}$ characteristic signals together as given in Figure 1a. Compared to $\mathrm{Mn}$-doped $\mathrm{CsPCl}_{3}$ crystals, neat host crystals show a more stable optical and structural response in time because both the host emission observed at $2.8 \mathrm{eV}$ (Figure 3c) and characteristic signals of the $\mathrm{CsPbCl}_{3}$ remain almost the same.

Neat $\mathrm{CsPbCl}_{3}$ host crystals (not doped ones with ratio of $\geq 63 \%$ ) were observed to be optically and structurally stable over time. On the other hand, Mn-doped perovskite crystals $(\leq 37 \%)$ showed both optical and structural instabilities. The driver for these instabilities was investigated through theoretical calculations, and it was found that Mn ions diffuse toward the crystal surface resulting in both optical and structural instabilities.

\section{CONCLUSIONS}

In this study, the influence of Mn dopants on the structural, vibrational, and optical properties of Cs-perovskite crystals was investigated by performing experimental characterization tools and state-of-the-art first-principles calculations. It was found that the presence of $\mathrm{Mn}$ ions leads to a structural transition from the $\mathrm{Cs}_{4} \mathrm{PbBr}_{6}$ to the $\mathrm{CsPCl}_{3}$ phase and opens an additional emission channel at $\sim 2.1 \mathrm{eV}$. On the other hand, PL intensity of the dopant-induced emission was found to decay exponentially over time. DFT calculations revealed that the additional PL peak simply stems from the Mn-originated midgap states and the decaying behavior of emission is a consequence of diffusive motion of $\mathrm{Mn}$ dopants toward the crystal surface. Time-dependent XRD and Raman measurements also revealed that formation of $\mathrm{MnO}_{2}$ at the surface and domains of the $\mathrm{Cs}_{4} \mathrm{PbCl}_{6}$ phase in the $\mathrm{CsPbl}_{3}$ host crystal also take place. As a result, this work provides a detailed understanding about the doping process of cesium lead perovskites including both its pre- and postdoping conditions.

\section{AUTHOR INFORMATION}

\section{Corresponding Author}

*E-mail: hasansahin@iyte.edu.tr.

\section{ORCID}

Baris Akbali: 0000-0002-6852-2193

Mustafa M. Demir: 0000-0003-1309-3990

Hasan Sahin: 0000-0002-6189-6707

Notes

The authors declare no competing financial interest.

\section{ACKNOWLEDGMENTS}

Computational resources were provided by TUBITAK ULAKBIM, High Performance and Grid Computing Center (TR-Grid e-Infrastructure). H.S. acknowledges financial support from the TUBITAK under Project No. 117F095.

\section{REFERENCES}

(1) Zhang, F.; Zhong, H.; Chen, C.; Wu, X.; Hu, X.; Huang, H.; Han, J.; Zou, B.; Dong, Y. Brightly luminescent and color-tunable colloidal $\mathrm{CH}_{3} \mathrm{NH}_{3} \mathrm{PbX}_{3}(\mathrm{X}=\mathrm{Br}, \mathrm{I}, \mathrm{Cl})$ quantum dots: Potential alternatives for display technology. ACS Nano 2015, 9, 4533.

(2) Protesescu, L.; Yakunin, S.; Bodnarchuk, M. I.; Krieg, F.; Caputo, R.; Hendon, C. H.; Yang, R. X.; Walsh, A.; Kovalenko, M. V. Nanocrystals of cesium lead halide perovskites $\left(\mathrm{CsPbX}_{3}, \mathrm{X}=\mathrm{Cl}, \mathrm{Br}\right.$, and I): Novel optoelectronic materials showing bright emission with wide color gamut. Nano Lett. 2015, 15, 3692.
(3) Akkerman, Q. A.; D’Innocenzo, V.; Accornero, S.; Scarpellini, A.; Petrozza, A.; Prato, M.; Manna, L. Tuning the optical properties of cesium lead halide perovskite nanocrystals by anion exchange reactions. J. Am. Chem. Soc. 2015, 137, 10276.

(4) Huang, H.; Bodnarchuk, M. I.; Kershaw, S. V.; Kovalenko, M. V.; Rogach, A. L. Lead halide perovskite nanocrystals in the research spotlight: Stability and defect tolerance. ACS Energy Lett. 2017, 2, 2071.

(5) Li, X. M.; Cao, F.; Yu, D. J.; Chen, J.; Sun, Z. G.; Shen, Y. L.; Zhu, Y.; Wang, L.; Wei, Y.; Wu, Y.; et al. All inorganic halide perovskites nanosystem: Synthesis, structural features, optical properties and optoelectronic applications. Small 2017, 13, 1603996.

(6) Kang, J.; Wang, L. High defect tolerance in lead halide perovskite CsPbBr3. J. Phys. Chem. Lett. 2017, 8, 489.

(7) Swarnkar, A.; Chulliyil, R.; Ravi, V. K.; Irfanullah, M.; Chowdhury, A.; Nag, A. Colloidal $\mathrm{CsPbBr}_{3}$ perovskite nanocrystals: Luminescence beyond traditional quantum dots. Angew. Chem. 2015, $127,15644$.

(8) Pan, A.; He, B.; Fan, X.; Liu, Z.; Urban, J. J.; Alivisatos, A. P.; He, L.; Liu, Y. Insight into the ligand-mediated synthesis of colloidal $\mathrm{Cs}_{\mathrm{PbBr}}$ perovskite nanocrystals: The role of organic acid, base, and cesium precursors. ACS Nano 2016, 10, 7943.

(9) Lignos, I.; Stavrakis, S.; Nedelcu, G.; Protesescu, L.; deMello, A. J.; Kovalenko, M. V. Synthesis of cesium lead halide perovskite nanocrystals in a droplet-based microfluidic platform: Fast parametric space mapping. Nano Lett. 2016, 16, 1869.

(10) Zhang, D.; Eaton, S. W.; Yu, Y.; Dou, L.; Yang, P. Solutionphase synthesis of cesium lead halide perovskite nanowires. J. Am. Chem. Soc. 2015, 137, 9230.

(11) Imran, M.; Di Stasio, F.; Dang, Z.; Canale, C.; Khan, A. H.; Shamsi, J.; Brescia, R.; Prato, M.; Manna, L. Colloidal synthesis of strongly fluorescent $\mathrm{Cs} \mathrm{PbBr}_{3}$ nanowires with width tunable down to the quantum confinement regime. Chem. Mater. 2016, 28, 6450.

(12) Amgar, D.; Stern, A.; Rotem, D.; Porath, D.; Etgar, L. Tunable length and optical properties of $\mathrm{CsPb}_{3}(\mathrm{X}=\mathrm{Cl}, \mathrm{Br}, \mathrm{I})$ nanowires with a few unit cells. Nano Lett. 2017, 17, 1007.

(13) Akkerman, Q. A.; Motti, S. G.; Kandada, A. R. S.; Mosconi, E.; D’Innocenzo, V.; Bertoni, G.; Marras, S.; Kamino, B. A.; Miranda, L.; De Angelis, F.; et al. Solution synthesis approach to colloidal cesium lead halide perovskite nanoplatelets with monolayer-level thickness control. J. Am. Chem. Soc. 2016, 138, 1010.

(14) Shamsi, J.; Dang, Z.; Bianchini, P.; Canale, C.; di Stasio, F.; Brescia, R.; Prato, M.; Manna, L. Colloidal synthesis of quantum confined single crystal $\mathrm{CsPbBr}_{3}$ nanosheets with lateral size control up to the micrometer range. J. Am. Chem. Soc. 2016, 138, 7240.

(15) Lv, L.; Xu, Y.; Fang, H.; Luo, W.; Xu, F.; Liu, L.; Wang, B.; Zhang, X.; Yang, D.; Hu, W.; et al. Generalized colloidal synthesis of high-quality, two-dimensional cesium lead halide perovskite nanosheets and their applications in photodetectors. Nanoscale 2016, 8, 13589.

(16) Nedelcu, G.; Protesescu, L.; Yakunin, S.; Bodnarchuk, M. I.; Grotevent, M. J.; Kovalenko, M. V. Fast anion-exchange in highly luminescent nanocrystals of cesium lead halide perovskites $\left(\mathrm{CsPbX}_{3}, \mathrm{X}\right.$ $=\mathrm{Cl}, \mathrm{Br}, \mathrm{I})$. Nano Lett. 2015, 15, 5635 .

(17) Brennan, M. C.; Zinna, J.; Kuno, M. Existence of a sizedependent stokes shift in $\mathrm{Cs}_{\mathrm{PbBr}}$ perovskite nanocrystals. ACS Energy Lett. 2017, 2, 1487.

(18) Bekenstein, Y.; Koscher, B. A.; Eaton, S. W.; Yang, P.; Alivisatos, A. P. Highly luminescent colloidal nanoplates of perovskite cesium lead halide and their oriented assemblies. J. Am. Chem. Soc. 2015, 137, 16008.

(19) Kovalenko, M. V.; Protesescu, L.; Bodnarchuk, M. I. Properties and potential optoelectronic applications of lead halide perovskite nanocrystals. Science 2017, 358, 745.

(20) He, X.; Qiu, Y.; Yang, S. Fully-inorganic trihalide perovskite nanocrystals: A new research frontier of optoelectronic materials. Adv. Mater. 2017, 29, 1700775. 
(21) Kulbak, M.; Cahen, D.; Hodes, G. How important is the organic part of lead halide perovskite photovoltaic cells? efficient $\mathrm{CsPbBr}_{3}$ cells. J. Phys. Chem. Lett. 2015, 6, 2452.

(22) Beal, R. E.; Slotcavage, D. J.; Leijtens, T.; Bowring, A. R.; Belisle, R. A.; Nguyen, W. H.; Burkhard, G. F.; Hoke, E. T.; McGehee, M. D. Cesium lead halide perovskites with improved stability for tandem solar cells. J. Phys. Chem. Lett. 2016, 7, 746.

(23) Ramasamy, P.; Lim, D.; Kim, B.; Lee, S.; Lee, M.; Lee, J. Allinorganic cesium lead halide perovskite nanocrystals for photodetector applications. Chem. Commun. 2016, 52, 2067.

(24) Song, J.; Xu, L.; Li, J.; Xue, J.; Dong, Y.; Li, X.; Zeng, H. Monolayer and few-layer all-inorganic perovskites as a new family of two-dimensional semiconductors for printable optoelectronic devices. Adv. Mater. 2016, 28, 4861.

(25) Wang, D.; Wu, D.; Dong, D.; Chen, W.; Hao, J.; Qin, J.; Xu, B.; Wang, K.; Sun, X. Polarized emission from $\mathrm{CsPbX}_{3}$ perovskite quantum dots. Nanoscale 2016, 8, 11565.

(26) Güner, T.; Topçu, G.; Savacı, U.; Genç, A.; Turan, S.; Sarı, E.; Demir, M. M. Polarized emission from $\mathrm{CsPBBr}_{3}$ nanowire embeddedelectrospun PU fibers. Nanotechnology 2018, 29, 135202.

(27) Song, J.; Li, J.; Li, X.; Xu, L.; Dong, Y.; Zeng, H. Quantum dot light-emitting diodes based on inorganic perovskite cesium lead halides $(\mathrm{CsPbX})$. Adv. Mater. 2015, 27, 7162.

(28) Li, G.; Rivarola, F. W. R.; Davis, N. J. L. K.; Bai, S.; Jellicoe, T. C.; de la Peña, F.; Hou, S.; Ducati, C.; Gao, F.; Friend, R. H.; et al. Highly efficient perovskite nanocrystal light-emitting diodes enabled by a universal crosslinking method. Adv. Mater. 2016, 28, 3528.

(29) Li, J.; Xu, L.; Wang, T.; Song, J.; Chen, J.; Xue, J.; Dong, Y.; Cai, B.; Shan, Q.; Han, B.; et al. 50-fold EQE improvement up to $6.27 \%$ of solution-processed all-inorganic perovskite $\mathrm{CsPbBr}_{3}$ QLEDs via surface ligand density control. Adv. Mater. 2017, 29, 1603885.

(30) Eaton, S. W.; Lai, M.; Gibson, N. A.; Wong, A. B.; Dou, L.; Ma, J.; Wang, L.; Leone, S. R.; Yang, P. Lasing in robust cesium lead halide perovskite nanowires. Proc. Natl. Acad. Sci. U. S. A. 2016, 113, 1993.

(31) Xu, Y.; Chen, Q.; Zhang, C.; Wang, R.; Wu, H.; Zhang, X.; Xing, G.; Yu, W. W.; Wang, X.; Xiao, M.; et al. Two-photon-pumped perovskite semiconductor nanocrystal lasers. J. Am. Chem. Soc. 2016, $138,3761$.

(32) Yakunin, S.; Protesescu, L.; Krieg, F.; Bodnarchuk, M. I.; Nedelcu, G.; Humer, M.; De Luca, G.; Fiebig, M.; Heiss, W.; Kovalenko, M. V. Low-threshold amplified spontaneous emission and lasing from colloidal nanocrystals of caesium lead halide perovskites. Nat. Commun. 2015, 6, 8056.

(33) Meinardi, F.; Akkerman, Q. A.; Bruni, F.; Park, S.; Mauri, M.; Dang, Z.; Manna, L.; Brovelli, S. Doped halide perovskite nanocrystals for reabsorption-free luminescent solar concentrators. ACS Energy Lett. 2017, 2, 2368.

(34) Norris, D. J.; Yao, N.; Charnock, F. T.; Kennedy, T. A. Highquality manganese-doped ZnSe nanocrystals. Nano Lett. 2001, 1, 3.

(35) Pradhan, N.; Goorskey, D.; Thessing, J.; Peng, X. An alternative of CdSe nanocrystal emitters: pure and tunable impurity emissions in ZnSe nanocrystals. J. Am. Chem. Soc. 2005, 127, 17586.

(36) Rice, W. D.; Liu, W.; Baker, T. A.; Sinitsyn, N. A.; Klimov, V. I.; Crooker, S. A. Revealing giant internal magnetic fields due to spin fluctuations in magnetically doped colloidal nanocrystals. Nat. Nanotechnol. 2016, 11, 137.

(37) Fainblat, R.; Barrows, C. J.; Hopmann, E.; Siebeneicher, S.; Vlaskin, V. A.; Gamelin, D. R.; Bacher, G. Giant excitonic exchange splittings at zero field in single colloidal CdSe quantum dots doped with individual $\mathrm{Mn}^{2+}$ impurities. Nano Lett. 2016, 16, 6371.

(38) Santra, P. K.; Kamat, P. V. Mn-doped quantum dot sensitized solar cells: a strategy to boost efficiency over $5 \%$. J. Am. Chem. Soc. 2012, 134, 2508.

(39) Erickson, C. S.; Bradshaw, L. R.; McDowall, S.; Gilbertson, J. D.; Gamelin, D. R; Patrick, D. L. Zero-reabsorption doped-nanocrystal luminescent solar concentrators. ACS Nano 2014, 8, 3461.

(40) Erwin, S. C.; Zu, L.; Haftel, M. I.; Efros, A. L.; Kennedy, T. A.; Norris, D. J. Doping semiconductor nanocrystals. Nature 2005, 436, 91.
(41) Norris, D. J.; Efros, A. L.; Erwin, S. C. Doped nanocrystals. Science 2008, 319, 1776.

(42) Pradhan, N.; Das Adhikari, S.; Nag, A.; Sarma, D. D. Luminescence, plasmonic, and magnetic properties of doped semiconductor nanocrystals. Angew. Chem., Int. Ed. 2017, 56, 7038.

(43) Pradhan, N.; Sarma, D. D. Advances in light-emitting doped semiconductor nanocrystals. J. Phys. Chem. Lett. 2011, 2, 2818.

(44) Bryan, J. D.; Gamelin, D. R. Doped semiconductor nanocrystals: synthesis, characterization, physical properties, and applications. Prog. Inorg. Chem. 2005, 54, 47.

(45) Pan, G.; Bai, X.; Yang, D.; Chen, X.; Jing, P.; Qu, S.; Zhang, L.; Zhou, D.; Zhu, J.; Xu, W.; et al. Doping lanthanide into perovskite nanocrystals: highly improved and expanded optical properties. Nano Lett. 2017, 17, 8005.

(46) Liu, M.; Zhong, G.; Yin, Y.; Miao, J.; Li, K.; Wang, C.; Xu, X.; Shen, C.; Meng, H. Aluminum-doped cesium lead bromide perovskite nanocrystals with stable blue photoluminescence used for display backlight. Adv. Sci. 2017, 4, 1700335.

(47) Zhou, D.; Liu, D.; Pan, G.; Chen, X.; Li, D.; Xu, W.; Bai, X.; Song, $\mathrm{H}$. Cerium and ytterbium codoped halide perovskite quantum dots: a novel and efficient downconverter for improving the performance of silicon solar cells. Adv. Mater. 2017, 29, No. 1704149.

(48) Hu, Q.; Li, Z.; Tan, Z.; Song, H.; Ge, C.; Niu, G.; Han, J.; Tang, J. Rare earth ion-doped $\mathrm{CsPBBr}_{3}$ nanocrystals. Adv. Opt. Mater. 2018, 6,1700864

(49) Van der Stam, W.; Geuchies, J. J.; Altantzis, T.; Van Den Bos, K. H. W.; Meeldijk, J. D.; Van Aert, S.; Bals, S.; Vanmaekelbergh, D.; de Mello Donega, C. Highly emissive divalent-ion-doped colloidal $\mathrm{CsPb}_{1-x} \mathrm{M}_{x} \mathrm{Br}_{3}$ perovskite nanocrystals through cation exchange. J. Am. Chem. Soc. 2017, 139, 4087.

(50) Guria, A. K.; Dutta, S. K.; Adhikari, S. D.; Pradhan, N. Doping $\mathrm{Mn}^{2+}$ in lead halide perovskite nanocrystals: successes and challenges. ACS Energy Lett. 2017, 2, 1014.

(51) Nag, A.; Chakraborty, S.; Sarma, D. D. To dope $\mathrm{Mn}^{2+}$ in a semiconducting nanocrystal. J. Am. Chem. Soc. 2008, 130, 10605.

(52) Wang, Q.; Zhang, X.; Jin, Z.; Zhang, J.; Gao, Z.; Li, Y.; Liu, S. F. Energy-down-shift $\mathrm{CsPbCl}_{3}: \mathrm{Mn}$ quantum dots for boosting the efficiency and stability of perovskite solar cells. ACS Energy Lett. 2017, 2, 1479.

(53) Mir, W. J.; Jagadeeswararao, M.; Das, S.; Nag, A. Colloidal Mndoped cesium lead halide perovskite nanoplatelets. ACS Energy Lett. 2017, 2, 537.

(54) Lin, C. C.; Xu, K. Y.; Wang, D.; Meijerink, A. Luminescent manganese-doped $\mathrm{CsPbCl}_{3}$ perovskite quantum dots. Sci. Rep. 2017, 7, 45906.

(55) Rossi, D.; Parobek, D.; Dong, Y.; Son, D. H. Dynamics of exciton-Mn energy transfer in $\mathrm{Mn}$-doped $\mathrm{CsPbCl}_{3}$ perovskite nanocrystals. J. Phys. Chem. C 2017, 121, 17143.

(56) Parobek, D.; Roman, B. J.; Dong, Y.; Jin, H.; Lee, E.; Sheldon, M.; Son, D. H. Exciton-to-dopant energy transfer in Mn-doped cesium lead halide perovskite nanocrystals. Nano Lett. 2016, 16, 7376.

(57) Liu, W.; Lin, Q.; Li, H.; Wu, K.; Robel, I.; Pietryga, J. M.; Klimov, V. I. $\mathrm{Mn}^{2+}$-doped lead halide perovskite nanocrystals with dual-color emission controlled by halide content. J. Am. Chem. Soc. 2016, 138, 14954.

(58) Karan, N. S.; Sarkar, S.; Sarma, D. D.; Kundu, P.; Ravishankar, N.; Pradhan, N. Thermally controlled cyclic insertion/ejection of dopant ions and reversible zinc blende/wurtzite phase changes in $\mathrm{ZnS}$ nanostructures. J. Am. Chem. Soc. 2011, 133, 1666.

(59) Acharya, S.; Sarkar, S.; Pradhan, N. Material diffusion and doping of Mn in wurtzite ZnSe nanorods. J. Phys. Chem. C 2013, 117, 6006.

(60) Kamat, P. V. Semiconductor nanocrystals: To dope or not to dope. J. Phys. Chem. Lett. 2011, 2, 2832.

(61) Zhu, J.; Yang, X.; Zhu, Y.; Wang, Y.; Cai, J.; Shen, J.; Sun, L.; Li, C. Room-temperature synthesis of Mn-doped cesium lead halide quantum dots with high Mn substitution ratio. J. Phys. Chem. Lett. 2017, 8, 4167. 
(62) Kresse, G.; Joubert, D. From ultrasoft pseudopotentials to the projector augmented-wave method. Phys. Rev. B: Condens. Matter Mater. Phys. 1999, 59, 1758.

(63) Blöchl, P. E. Generalized gradient approximation made simple. Phys. Rev. B: Condens. Matter Mater. Phys. 1994, 50, 17953.

(64) Kresse, G.; Hafner, J. Numerical computations have been carried out by using VASP software. Phys. Rev. B: Condens. Matter Mater. Phys. 1993, 47, 558.

(65) Kresse, G.; Furthmüller, J. Ab initio force constant approach to phonon dispersion relations of diamond and graphite. Phys. Rev. B: Condens. Matter Mater. Phys. 1996, 54, 11169.

(66) Perdew, J. P.; Zunger, A. Self-consistent equations including exchange and correlation effects. Phys. Rev. B: Condens. Matter Mater. Phys. 1981, 23, 5048.

(67) Ceperley, D. M.; Alder, B. Ground state of the electron gas by a stochastic method. Phys. Rev. Lett. 1980, 45, 566.

(68) Henkelman, G.; Arnaldsson, A.; Jónsson, H. A fast and robust algorithm for Bader decomposition of charge density. Comput. Mater. Sci. 2006, 36, 354.

(69) Saidaminov, M. I.; Almutlaq, J.; Sarmah, S.; Dursun, I.; Zhumekenov, A. A.; Begum, R.; Pan, J.; Cho, N.; Mohammed, O. F.; Bakr, O. M. Pure $\mathrm{Cs}_{4} \mathrm{PbBr}_{6}$ : Highly luminescent zero-dimensional perovskite solids. ACS Energy Lett. 2016, 1, 840.

(70) Yin, J.; Zhang, Y.; Bruno, A.; Soci, C.; Bakr, O. M.; Brédas, J.-L.; Mohammed, O. F. Intrinsic lead ion emissions in zero-dimensional $\mathrm{Cs}_{4} \mathrm{PbBr}_{6}$ nanocrystals. ACS Energy Lett. 2017, 2, 2805.

(71) Carabatos-Nédelec, C.; Oussaïd, M.; Nitsch, K. Raman scattering investigation of cesium plumbochloride, $\mathrm{CsPbCl}_{3}$, phase transitions. J. Raman Spectrosc. 2003, 34, 388.

(72) Akkerman, Q. A.; Park, S.; Radicchi, E.; Nunzi, F.; Mosconi, E.; De Angelis, F.; Brescia, R.; Rastogi, P.; Prato, M.; Manna, L. Nearly monodisperse insulator $\mathrm{Cs}_{4} \mathrm{PbX}_{6}(\mathrm{X}=\mathrm{Cl}, \mathrm{Br}, \mathrm{I})$ nanocrystals, their mixed halide compositions, and their transformation into $\mathrm{CsPb}_{3}$ nanocrystals. Nano Lett. 2017, 17, 1924.

(73) Dalpian, G. M.; Chelikowsky, J. R. Self-purification in semiconductor nanocrystals. Phys. Rev. Lett. 2006, 96, 226802.

(74) Gao, T.; Fjellvåg, H.; Norby, P. A comparison study on Raman scattering properties of $\alpha$ - and $\beta-\mathrm{MnO}_{2}$. Anal. Chim. Acta 2009, 648, 235.

(75) Akbali, B.; Topcu, G.; Guner, T.; Ozcan, M.; Demir, M. M.; Sahin, H. CsPbBr 3 perovskites: Theoretical and experimental investigation on water-assisted transition from nanowire formation to degradation. Phys. Rev. Materials 2018, 2, 034601.

(76) Liu, Z.; Bekenstein, Y.; Ye, X.; Nguyen, S. C.; Swabeck, J.; Zhang, D.; Lee, S.-T.; Yang, P.; Ma, W.; Alivisatos, A. P. Ligand mediated transformation of cesium lead bromide perovskite nanocrystals to lead depleted $\mathrm{Cs}_{4} \mathrm{PbBr}_{6}$ nanocrystals. J. Am. Chem. Soc. 2017, 139, 5309. 